\title{
The definition and evaluation of the skills required to obtain a patient's history of illness: the use of videotape recordings
}

\author{
J. ANDERSON \\ M.D., F.R.C.P. \\ J. L. DAY \\ M.B., M.R.C.P. \\ M. A. C. Dowling \\ K. W. Pettingale \\ M.R.C.S., L.R.C.P. \\ M.B., M.R.C.P. \\ Department of Medicine, King's College Hospital Medical School, London, S.E.5
}

\begin{abstract}
Summary
Videotape recording apparatus was used to make records of case histories obtained from patients by students and doctors. These records were studied in order to identify the skills required to obtain a patient's history of illness. Each skill was defined. A questionnaire was developed in order to assess these skills and three independent observers watched the records of eighteen students and completed a questionnaire for each. The results of this were analysed for reliability and reproducibility between examiners. Moderate reliability and reproducibility were demonstrated. The questionnaire appeared to be a valid method of assessment and was capable of providing significant discrimination between students for each skill. A components analysis suggested that the marks for each skill depend on an overall impression obtained by each examiner and this overall impression is influenced by different skills for each examiner.
\end{abstract}

\section{Introduction}

The ability to obtain a patient's history of illness is an important function of any doctor. Much of a medical student's time is spent in attempting to become proficient in obtaining a patient's history but surprisingly there are no clear-cut definitions of the required skills. Within lists of aims and objectives of medical education, statements about patient-history-taking give no guidance to students or their tutors as to what is required of them in terms of skills to be acquired or the standard to be reached (A.A.M.C. Statement, 1953; Royal Commission, 1968). The main objectives in taking a patient's history would appear to be (1) to obtain sufficient information to reach an accurate diagnosis in the light of subsequent findings. (2) To obtain sufficient knowledge of a patient's psychological and social background as is required for short- and longterm management of the patient. (3) To establish a satisfactory doctor/patient relationship which will enable a complete history to be taken and the later management to be carried out.

Doctors within different specialties may place different emphasis on each of these objectives but all three are essential for adequate patient care. Students and tutors may easily recognize these objectives but not the nature and standard of skills required to achieve them. Without further definition, evaluation of these skills such as that which takes place in the final examination may be haphazard. To define and evaluate the skills involved requires that the student be observed demonstrating these skills (Hinz, 1966). Until recently attempts to observe students taking a history have been confined to observing the student whilst standing beside him or rarely by the use of a one-way mirror. Such methods have certain disadvantages which include the interference by the presence of a third party and the lack of any replay facility. There is no possibility for the student to see himself or have facets of his interview illustrated to him. The use of videorecording apparatus offers an instrument whereby observation can be undertaken outside the interview room with replay facilities which allow interviews to be reviewed if necessary on a number of occasions.

The advantages of videotape as a recorder and a tool for self evaluation have been well described (Wilmer, 1968; Trethowan, 1968; Balfour Sclare \& Thompson, 1968).

This paper describes the use of videotape recording for observations of interviews and the identification and evaluation of the techniques required to obtain a case history.

\section{Method}

A preliminary study of a number of videorecordings of students and doctors taking case histories from patients was performed. These 
recordings revealed certain errors and omissions which led to failure or partial success of certain interviews. Comparison of these recordings with more successful interviews led to a definition of skills which appeared to be necessary if a patient's history is to be satisfactorily taken. To assess whether such skills can be observed and evaluated by independent observers a questionnaire was developed. This questionnaire was divided into a number of sections, each containing several questions. Each section was devoted to the specific skills which are defined below. In addition to these main sections one question was asked to give an overall impression of the history taken and one to give an estimate of the ease with which the case history could be obtained from the patient concerned. Each interview was then examined by three observers. Each observer was a lecturer with widely different medical experience working on the Medical Unit. They watched eighteen pre-clinical students taking case histories from different patients. Each patient was invited to participate and was informed of the presence of a camera. The camera was fixed in an unobtrusive position and the patient and interviewer left alone. The microphone was placed between patient and student. Normal room lighting was used and no patient was interviewed on more than one occasion. The student was asked to take a case history in the normal way and to summarize the interview on its completion. No time limit was set nor additional instruction given to the participants. Each interview and summary was recorded on a separate videotape. The examiners were asked to complete a questionnaire after watching each tape. They were instructed to complete the questionnaire, with the exception of the section devoted to the summary, before the summary was seen so that judgment about the method of the interview was not influenced by the evaluation of the student's subsequent summary or interpretation. No conferring or discussion about any of the interviews took place. Each section of the questionnaire was assigned an equal weight of marks. The marks for each section and total marks were analysed for reliability and reproducibility between examiners. Correlations between the scores allocated by different examiners to different sections and the total marks were calculated and expressed as coefficients. Six interviews were marked by the three observers on two occasions which were separated by an 8-week time-interval. A comparison between total marks and overall impression of the examiners was made to give an estimate of the validity. Differences between examiners and discrimination between students was tested by analysis of variance. Interdependence of scores for each section was assessed by components analysis (Horst, 1965) and common factors were examined.

\section{Results}

\section{Definition of skills}

Review of a number of tapes in the pilot survey led to the following definition of skills required for the student to take a good medical history:

Skill in the ability to establish the maximum degree of comprehension between patients and doctors; the ability to obtain essential historical information; the ability to interview in logical fashion; the ability to listen to the patient; the ability to interrupt the patient; the ability to observe non-verbal cues; the ability to establish a good relationship with a patient; and the ability to interpret the interview accurately.

\section{(1) The ability to establish the maximum degree of comprehension between patients and doctors}

For any dialogue or exchange of information to take place it is self-evident that the participants understand one another. It is for the interviewer to make sure that the patient understands him and he understands the patient. Regional dialects or the use of a non-native tongue will naturally impede understanding. The interviewer should only use words and phrases which have the same meaning to himself and his patient. This will prohibit the use of medical jargon. Since the vocabulary of the patient cannot be predetermined the interviewer must be aware of different interpretations of words and phrases used by patients from different backgrounds.

\section{(2) The ability to obtainessential historical information}

This is the ability without which the first two objectives in taking a case history, i.e. to obtain sufficient information, are unobtainable. This ability might appear to be that of simple recall of the necessary questions to be asked. However, there is an assumption that given the ability to recall a checklist of questions, such as that provided at the student's first introduction to clinical practice, the ability to actually obtain answers will be ensured. Such an ability will undoubtedly be dependent on the other skills described.

\section{(3) The ability to interview in logical fashion}

It would seem necessary if the information is to be obtained from the patient with the greatest ease that each interview should progress in a logical way. It is evident that observation techniques allowed us to observe analytical reasoning and not intuitive reasoning. The difference between the convergent and divergent thinker was highlighted by the observational technique employed but there was often little difference between the two when the data obtained by the interviews was compared. However, it 
appeared that the patients, who like ourselves are observers, responded much more easily to the convergent thinker and became bewildered by the divergent. With the latter the interview was frequently unduly prolonged and greater opportunity for misunderstanding was possible.

\section{(4) The ability to listen to a patient}

Failure of the interviewer to listen carefully to the patient was observed on many occasions. Not only were words and phrases misheard and as a result misunderstood by the interviewer, but also the interview was frequently prolonged by the use of unnecessary questions and the search for information which the patient had already given. Verbal cues which could have given additional useful information were frequently missed. The interviewer must have the ability not only to listen to words used by the patients but the way in which they are used.

\section{(5) The ability to interrupt}

The interviewer requires the ability to know (a) when to interrupt, (b) when not to interrupt and (c) the appropriate word or phrases required in order to interrupt tactfully. Some interruption is usually required to guide the patient into discussion to achieve the objectives of the interview. In general the cultural background of our students is one which has contained the behavioural directive to avoid prying into other people's affairs. Students not used to interviewing have been conditioned not to question people closely and this was particularly apparent when watching early clinical students. Students were listeners rather than interviewers, allowing the patients to talk entirely along their own lines without interruption or redirection. To achieve the skill of interruption the students not only have to be made aware of this need but also provided in many instances with the vocabulary to interrupt in a tactful way, yet without using leading questions and phrases. In many instances interviews became structureless because of the inability to find such phrases or to redirect a talkative patient. On the other hand useful information was lost by excessive interruption and some or many symptoms were not expressed.

\section{(6) The ability to observe non-verbal cues}

In daily conversations many of the impressions formed by the two participants spring from the interchange of non-verbal cues. In an interview the same exchange takes place and will influence greatly the course of the interview, the relationship with the patient and the subsequent interpretation of the interview. Using our observational techniques it would be foolhardy to claim that all such cues were seen by observers but many were, e.g. a patient on the verge of tears. Abilities in this sphere were three.
Firstly, the ability to observe the non-verbal cues, secondly, judgment as to whether to respond and, thirdly, choice of the method of the response.

\section{(7) The ability to establish a good doctor-patient relationship between the patient and the student}

This is the thorny problem of empathy or bedside manner established by the interviewer with the patient and implied in the description of history taking as 'an art'. It appeared to us that much of this nebulous entity was compounded of many of the factors described above and given the skills described above a good relationship with the patient followed. In addition, however, the wording and tone of voice of the interviewer should contain a degree of sympathy and acceptance of patients' attitudes. He should avoid inappropriate expression of his own feelings or judgments.

\section{(8) The ability to interpret the interview}

In relation to the objectives of taking a case history this is of the utmost importance. The student requires an ability to evaluate the observations he has made. To do this he needs to recall accurately the details of the interview. Only too frequently when the summary given by the interviewer was compared with the observations of the actual interview considerable errors of recall were demonstrated. The students need to be able to evaluate the observations and data they have recorded and formulate these into accepted descriptive and medical diagnostic terms.

\section{Results of questionnaire assessment}

The total scores and scores for each section of the questionnaire were first examined for the reliability between judgments of different examiners. The correlation between each examiner is expressed as a correlation coefficient for each pair of examiners. The coefficients for each section and total marks are shown in Table 1.

Of the twenty-seven correlation coefficients only five are non-significant at the $95 \%$ level. These five each occurred in different sections and the other two coefficients in that section were significant. There was considerable variation between the correlation coefficients within the same sections and for different sections. For example, the section evaluating the ability to observe non-verbal cues had coefficients of 0.79 and 0.60 and 0.49 and the relationship between the patient and the interviewer 0.64, 0.76 and 0.38 . When the coefficients for the total marks were examined $(0.76,0.52,0.78)$ there was some improvement. A further correlation between the total marks awarded by all the examiners and the separate overall impression of the standard history obtained by the student gave a coefficient of $0 \cdot 73$. 
TABLE 1. Correlation co-efficients between scores given by pairs of examiners

\begin{tabular}{|c|c|c|c|c|c|c|}
\hline \multirow[t]{2}{*}{ Correlation of marks for student skill } & \multicolumn{2}{|c|}{$1 / 2$} & \multicolumn{2}{|c|}{$1 / 3$} & \multicolumn{2}{|c|}{$2 / 3$} \\
\hline & $R$ value & $P$ value & $\mathbf{R}$ value & $P$ value & $\mathbf{R}$ value & $P$ value \\
\hline \multicolumn{7}{|l|}{ Ability to: } \\
\hline 1. Promote maximum degree of comprehension & 0.59 & $<0.02$ & 0.66 & $<0.01$ & $0 \cdot 36$ & NS \\
\hline 2. Obtain essential historical information & 0.63 & $<0.01$ & 0.55 & $<0.02$ & 0.61 & $<0.01$ \\
\hline 3. Interview logically & 0.56 & $<0.02$ & 0.57 & $<0.02$ & 0.27 & NS \\
\hline 4. Listen carefully & 0.51 & $<0.05$ & $0 \cdot 47$ & $<0.05$ & $0 \cdot 15$ & NS \\
\hline 5. Interrupt & $0 \cdot 10$ & NS & 0.53 & $<0.05$ & 0.50 & $<0.05$ \\
\hline 6. Observe for non-verbal clues & 0.49 & $<0.05$ & 0.79 & $<0.001$ & 0.60 & $<0.01$ \\
\hline 7. Establish good relationship & 0.64 & $<0.01$ & 0.76 & $<0.001$ & $0 \cdot 38$ & NS \\
\hline 8. Summarize interview & 0.63 & $<0.01$ & 0.64 & $<0.01$ & 0.61 & $<0.01$ \\
\hline Totals & $0 \cdot 76$ & $<0.001$ & 0.52 & $<0.05$ & $0 \cdot 78$ & $<0.001$ \\
\hline
\end{tabular}

NS $=$ Not significant

To test whether significant differences between the performance of these skills by different students could be observed by different examiners an analysis of variance was carried out. Such analysis should demonstrate differences between the scores for different students, differences between examiners' scores for the same students and a comparison between the two variances. Results of the analysis of scores for each section and the total marks are shown in Table 2. For all sections of the questionnaire there was a significant difference between the scores of the individual students. Only three of the sections showed a significant difference between the scores given by different examiners to the same student. These sections are those which assess the ability to promote maximum understanding, to observe non-verbal cues and to establish a good relationship. In these three, however, the variance attributable to examiner variation was less than that attributable to student variation.

The sections providing the greatest variation between the scores of different students and least variations between different examiners were those describing the ability (1) to establish essential information, and (2) to interpret the interview. There were correspondingly good results for the total marks. In order to test for reproducibility of examiners' scores, the tapes of nine students were marked before and after an interval of 2 months. A correlation coefficient of 0.60 ( $P$ less than 0.001 ) between scores was again given by the same examiner to each student before and after this interval. On testing the difference between examiners' scores before and after, a mean difference in scores of $9.7 \%$ (SD 7.48, SEM 1.44) was obtained.

Since it was suspected that the marks given might not reflect the ability of the student but the ease with which the patient gave a history, examiners were invited to record on a five-point scale $(5=$ very easy, $1=$ very difficult etc.) whether the patient was easy to obtain a history from. The correlation coefficient between these scores and the total marks was - 0.287 $(P$ less than 0.035) indicating a small effect by the patient on the overall marks.

Components analysis was carried out, firstly, to determine the degree of inter-dependence of the

TABLE 2. Comparison of differences between individual examiners with differences between individual students

\begin{tabular}{|c|c|c|c|c|}
\hline \multirow[t]{2}{*}{ Student skills } & \multicolumn{2}{|c|}{$\begin{array}{c}\text { Differences } \\
\text { between students }\end{array}$} & \multicolumn{2}{|c|}{$\begin{array}{c}\text { Differences } \\
\text { between examiners }\end{array}$} \\
\hline & Variance ratio & Significance $(P)$ & Variance ratio & Significance $(P)$ \\
\hline $\begin{array}{l}\text { Ability to: } \\
\text { 1. Establish understanding } \\
\text { 2. Establish information } \\
\text { 3. Interview logically } \\
\text { 4. Listen } \\
\text { 5. Interrupt } \\
\text { 6. Observe non-verbal cues } \\
\text { 7. Establish good relationship } \\
\text { 8. Interpret the interview }\end{array}$ & $\begin{array}{l}4 \cdot 58 \\
3 \cdot 65 \\
2 \cdot 61 \\
2 \cdot 79 \\
2 \cdot 3 \\
3 \cdot 55 \\
5 \cdot 15 \\
4 \cdot 91\end{array}$ & $\begin{array}{l}<0.001 \\
<0.001 \\
<0.05 \\
<0.01 \\
<0.01 \\
<0.001 \\
<0.001 \\
<0.001\end{array}$ & $\begin{array}{l}7.88 \\
0.90 \\
1.99 \\
0.33 \\
3.09 \\
7.02 \\
5.69 \\
1.39\end{array}$ & $\begin{array}{r}<0.01 \\
\text { NS } \\
\text { NS } \\
\text { NS } \\
\text { NS } \\
<0.01 \\
<0.01 \\
\text { NS }\end{array}$ \\
\hline $\begin{array}{l}\text { Total: } \\
\text { Degrees of freedom }\end{array}$ & $\begin{array}{ll}6 \cdot 36 & \\
& \text { Upp } \\
& \text { Lov }\end{array}$ & $\begin{array}{l}-0.001 \\
\text { er } 17\end{array}$ & 0.19 & $\begin{array}{ll} & \text { NS } \\
\text { ver } 2 & \\
\text { ver } 37 & \end{array}$ \\
\hline
\end{tabular}


scores given for each section, secondly, to determine whether the performance in any particular section so influenced the scores in other sections as to make them non-contributory to the final mark, and, thirdly, to determine how many components or factors contributed to the final score. The scores of each examiner were examined separately and correlation matrices produced. The eigan value and percentage of the variance provided by each component was calculated (Table 3). It can be seen that a very large percentage of the variance is due to one component in the case of each examiner $(58.9 \%$, $43.3 \%$ and $61.9 \%$ ). There thus seems to be a large general factor influencing the total scores.

This factor was then analysed to see which sections of the questionnaire were providing the major contribution (Table 4). Table 4 gives the analysis before rotation and Table 5 after rotation of the matrices. In both instances the sections contributing

TABLE 3. The percentage variance accounted for by each of the principal components for each examiner

\begin{tabular}{cccc}
\hline $\begin{array}{c}\text { Component } \\
\text { No. }\end{array}$ & $\begin{array}{c}\text { Examiner } \\
1\end{array}$ & $\begin{array}{c}\text { Examiner } \\
2\end{array}$ & $\begin{array}{c}\text { Examiner } \\
3\end{array}$ \\
\hline 1 & 58.9 & 43.3 & 61.9 \\
2 & 13.8 & 19.8 & 10.8 \\
3 & 8.4 & 11.3 & 8.5 \\
4 & $7 \cdot 7$ & 9.6 & 6.9 \\
5 & 5.2 & 6.0 & 5.5 \\
6 & 3.4 & 4.4 & 3.8 \\
7 & 1.6 & 3.7 & 2.0 \\
8 & 0.9 & 1.9 & 0.7 \\
\hline
\end{tabular}

TABLE 4. Analysis of the sections contributing to the principal component for each examiner before rotation of the matrices

\begin{tabular}{cccc}
\hline Section & $\begin{array}{c}\text { Examiner } \\
1\end{array}$ & $\begin{array}{c}\text { Examiner } \\
2\end{array}$ & $\begin{array}{c}\text { Examiner } \\
3\end{array}$ \\
\hline 1 & 0.88 & 0.73 & 0.80 \\
2 & 0.88 & 0.70 & 0.71 \\
3 & 0.71 & 0.56 & 0.66 \\
4 & 0.84 & 0.70 & 0.75 \\
5 & 0.69 & 0.71 & 0.84 \\
6 & 0.82 & 0.50 & 0.91 \\
7 & 0.59 & 0.39 & 0.73 \\
8 & 0.68 & 0.85 & 0.87 \\
\hline
\end{tabular}

TABLE 5. Analysis of the sections contributing to the principal components for each examiner after rotation of the matrices

\begin{tabular}{cccc}
\hline \multirow{2}{*}{ Section } & $\begin{array}{c}\text { Examiner } \\
1\end{array}$ & $\begin{array}{c}\text { Examiner } \\
2\end{array}$ & $\begin{array}{c}\text { Examiner } \\
3\end{array}$ \\
\hline 1 & 0.52 & 0.21 & 0.34 \\
2 & 0.79 & $0 \cdot 16$ & 0.47 \\
3 & 0.81 & 0.43 & $0 \cdot 16$ \\
4 & 0.53 & 0.88 & $0 \cdot 10$ \\
5 & 0.12 & 0.73 & 0.70 \\
6 & 0.57 & $0 \cdot 14$ & 0.72 \\
7 & 0.33 & 0.06 & 0.90 \\
8 & 0.84 & 0.80 & 0.68 \\
\hline
\end{tabular}

to this major factor were different in the case of each examiner. Before rotation the major contribution was provided by sections $1,2,4$ and 6 for examination 1 , sections $8,1,5$ and 2 for examiner 2 , and sections $6,8,1$ and 5 for examiner 3 . After rotation the major contributions are sections 8,3 and 2 for examiner 1 , sections 4,8 and 5 for examiner 2 , and sections 7, 6 and 5 for examiner 3 . Thus all sections except section 1 played a large part in the formation of a general factor and the sections differed considerably for each examiner. There is no one section that provides so little contribution that it can be held to play no part in the formation of this general factor. Only the large general factor could be identified by this analysis. When a second factor was sought no consistency was found. This general factor could be considered as an overall impression of the history which was taken. Correlation between the scores given for the overall impression and the scores provided by this general factor gave coefficients of correlation for each examiner of $0.85,0.65$ and 0.78 respectively.

\section{Student response}

No antipathy was provoked by the method of recording. All students welcomed the opportunity to review their own performance, and approved the use of videotape recording method of learning interview techniques. It was suggested that selfevaluation was often of as much value as tutorguided discussion. The presence of the camera did not appear to interfere with the flow of the interview. Only one student admitted that he was inhibited by the method of recording the interview.

\section{Discussion}

The method of eliciting a case history is not standardized. Individual practitioners are bound to vary in their techniques but certain basic skills must be necessary. Using traditional methods of teaching, skill in taking a case history is achieved either by observing more experienced clinicians and untutored imitation of techniques which appear to be successful, or by the individual experience of the student himself. The clinicians he observes will have learnt their skills in a similar way. Evaluation of a standard of skill achieved in taking a history is largely limited to a recital of information obtained from a patient and interpretation of this history in diagnostic terms. The standard is set by judgments of the adequacy and accuracy of this information. These judgments can only be based on the examiner's reliance on his or her or a colleague's interpretation of a history taken under different circumstances. No judgment can be made on the method of taking a history or of the relationship established with the patient without direct observation. 
Use has been made of videotape for learning interview techniques largely in the psychiatric field. In most reviews description is confined to the use of videotape for learning (Kornfield \& Kolb, 1964; Wagner, 1967; Ramey, 1968). Yonge (1965) suggests some of the attitudes required by the interviewer for successful interviewing but it is dubious whether these can be recognized or reliably assessed by observers. Hinz (1966) has provided a check-list for use during observation which lists more elementary skills but like Charvat, McGuire \& Parsons (1968) he concentrates mainly on the importance of establishing essential information and gives little definition of the skills required to obtain such information.

To the more expert all the skills described may appear self-evident and this would appear to justify their inclusion within the list of definition of skills. Such definition provides the basis for improved evaluation and learning of skills. The analysis of questionnaire results demonstrated that moderate agreements could be reached by different examiners when they were directed to mark each skill. The results of analysis of variance suggest that these skills are capable of observation and discrimination by different examiners, in spite of their obvious subjectivity. These examiner differences are greatest when the examiners are called upon to judge the abilities of the student to establish the maximum understanding, to observe non-verbal cues and establish a good relationship with the patient. The discrimination between students was greatest and differences between examiners least for those sections related to obtaining historical information and interpretation of the interview. These are the areas in which examiners are most familiar when evaluating by traditional methods case histories obtained by students.

It would appear from the components analysis that the scores given to each skill are not independent. There is no section which excessively influences any other section however, and none which plays so little part in the overall score that it can be considered insignificant.

Direct observation with a questionnaire does appear to provide a quantitative assessment of students' abilities to take a case history. The good correlations of total marks and the general factor from component analysis with the examiners' overall impression of the history does suggest that such a method is a valid form of assessment. Wilson et al. (1969) used videotape recordings to investigate the variability between examiners when judging the performance of physical examinations. This was slightly less than that described in this paper but was probably improved by using the same patients for different students. This would be impossible for the evaluation of interviewing skills because of the effects of rehearsal on the patient's response to questioning. The influence of the patient on the overall mark is only small. The reproducibility between initial and later scores by examiners is good.

The subjectivity of examiners is well illustrated by the components analysis. It is apparent that each examiner's overall impression is influenced by different aspects of the history. An interesting possibility arises from study of the grouping of the sections contributing most to each examiner's large general factor. For examiner 1 the sections describing the student's ability to interpret the interview (section 8), interview logically (section 3 ) and obtain the necessary data (section 2 ) are the principal contributors to his large general factor or overall impression. These contrast with those for examiner 3 which are the student's ability to establish a good relationship (section 7), observe non-verbal cues (section 6) and ability to interrupt (section 5). This great difference emphasises the examiner differences and might suggest that examiner 1 is most influenced by the organic aspects of the history and the way in which it is taken, and examiner 3 more influenced by the psychosocial aspects of the history. It is possible, therefore, that the techniques described above reveal information not only about the students but also about the examiners. They provide a tool for measuring the attitudes of undergraduate and postgraduate students towards the problems involved in taking a case history. The need for more than one observer is reinforced.

It would appear, therefore, that in spite of the subjective nature of assessment of interview techniques, the use of a questionnaire with direct observation can provide a moderately reliable, reproducible, and valid evaluation of these techniques when several examiners are used. Prior definition of the skills is important and the combination of such definitions with an evaluation technique provide a useful addition to the teaching of clinical medicine. Such a combination could be used to evaluate students early on in their clinical training. The use of students' own recordings could provide a means of instruction to enable them to reach the objectives more rapidly, and to identify those areas in which they are deficient. Training of the examiners and familiarity with the techniques are likely to raise the competence and overall ability of the examiners.

\section{Acknowledgments}

We gratefully acknowledge the support of Hoechst Pharmaceuticals Ltd., for this study, and the advice of $\mathrm{Mr}$ B. S. Everitt, of the Biometrics Unit, Institute of Psychiatry, Maudsley Hospital. 


\section{References}

A.A.M.C. Statement (1953). Objectives in medical education. Journal of Medical Education, 28, 57.

Balfour Sclare, A. \& Thompson, G.O.B. (1968) Use of closed circuit television in teaching psychiatry to medical students. British Journal of Medical Education, 2, 226.

Charvat, J., McGuire, C. \& Parsons, V. (1968) Review of the Value and Uses of Examinations in Medical Education. WHO, 52.

Hinz, C.F. (1966). Direct observations as a means of teaching and evaluating clinical skills. Journal of Medical Education, 41, 150.

HoRst, P. (1965) Factor Analysis of Data Matrices. Chap. 18. Sec. 18.4. Holt, London.

KoRNFIELD, D.S. \& KolB, L.C. (1964) Use of closed circuit television for the teaching of psychiatry. Journal of Nervous and Mental Diseases, 138, 452.
RameY, J.W. (1968). Teaching medical students by videotape simulation. Journal of Medical Education, 43, 55.

Royal Commission on Medical Education (1968), HMSO, London.

TreThowaN, W.H. (1968) Teaching psychiatry by closedcircuit television. Journal of Psychiatry, 114, 517.

WAGNER, H. N. (1967) Videotape in the teaching of medical education. Journal of Medical Education, 42, 1055.

Wilmer, H.A. (1968) Television as a participant recorder. American Journal of Psychiatry, 124, 1157.

Wilson, G.M., Lever, R., McG. Harden, R., Robertson, J.I.S. \& MACRitchie, U. (1969) Examination of clinical examiners. Lancet, $\mathrm{i}, 37$.

Yonge, K.A. (1965) The use of closed circuit television for the teaching of psychotherapeutic interviewing to medical students. Canadian Medical Association Journal, 92, 747. 
Morson, B.C. (1962) Precancerous lesions of upper gastrointestinal tract. Journal of the American Medical Association, 179, 311.

OLDFIELD, M.C. (1954) Association of familiary polyposis of the colon with multiple sebaceous cysts. British Journal of Surgery, 41, 534.

Parsons, R.L. \& Savin, J.A. (1968) Pemphigoid and malignancy. British Journal of Cancer, 22, 669.

Peterka, E.S., LynCh, F.W. \& Goltz, R.W. (1961) Association between Bowen's disease and internal cancer. Archives of Dermatology, 84, 623.

Peutz, J.L.A. (1921) On a very remarkable case of familial polyposis of the mucous membrane of the intestinal tract and nasopharynx accompanied by peculiar pigmentations of the skin and mucous membranes. Nederlandsch maandschrift voor geneeskunde, 10, 134.

POLLITZER, S. (1890) International Atlas of Rare Skin Diseases. (Ed. by Morris.) Lewis, London.

PURDY, M.J. (1959) Erythema gyratum repens. Report of a case. Archives of Dermatology, 80, 590.

RAJKA, G. (1966) Investigation of patients suffering from generalised pruritus, with special reference to systemic disease. Acta dermato-venereologica, 46, 190.

ReINGOLD, I. (1966) Cutaneous metastases from internal carcinoma. Cancer (New York), 19, 162.

RHODES, E.L. (1970) Palmar and plantar seed keratoses and internal malignancy. British Journal of Dermatology, 82, 361.

RONCHESE, F. (1943) Ichthyosiform atrophy of the skin in Hodgkin's disease. Archives of Dermatology and Syphilis, 50, 85.

RONCHESE, F. (1965) Keratoses, cancer and 'The Sign of Leser Trelat'. Cancer (New York), 18, 1003.

Rothman, S. (1958) Pruritus as a symptom of internal disease. American Practitioner and Digest of Treatment, 9, 226.

SHAMMY, H.K. (1963) Bronchiolar carcinoma presenting as erythema gyratum perstans. Proceedings of the Royal Society of Medicine, 56, 904.

Shelley, W.B. (1962) Auto-immune mechanism in clinical dermatology. Archives of Dermatology, 86, 27.

Shelley, W.B. \& HURLEY, H.J. (1960) An unusual autoimmune syndrome. Archives of Dermatology, 81, 889.

Shine, L. \& Allison, P.R. (1966) Carcinoma of the oesophagus with tylosis. Lancet, i, 951.
SNeddon, I.B. (1955) Acquired ichthyosis and Hodgkin's disease. British Medical Journal, 1, 763.

SNEDDON, I.B. \& ROBERTS, J.B.M. (1962) An incomplete form of acanthosis nigricans. Gut, 3, 269.

Staley, C.J. (1961) Gardner's syndrome. Simultaneous occurrence of polyposis coli, osteomatosis and soft tissue tumours. Archives of Surgery, 82, 420.

Stertz, G. (1916) Polymyositis. Berliner klinische Wochenschrift, 53, 489.

SuMmerLy, R. (1964) Figurate erythema and neoplasia. British Journal of Dermatology, 76, 370.

Swanson, P., Schorr, W.F., MaGnin, G.E. \& DovenBARGER, W. (1918) Dermatological manifestations of the S.V.C. syndrome. Archives of Dermatology, 98, 628.

Thomson, J. \& STANKLeR, L. (1970) Erythema gyratum repens: reports of two further cases associated with carcinoma. British Journal of Dermatology, 82, 406.

Tighe, S.M. (1960) Pseudo-acanthosis nigricans. Lancet, ii, 1422.

Tillman, W.G. (1950) Herpes gestationis with hydatidiform mole and chorion epithelioma. British Medical Journal, 1, 1471.

ToBIAs, N. (1951) Dermatitis herpetiformis associated with visceral malignancy. Urologic and Cutaneous Review, 55, 352.

Tromovitch, T.A., Jacobs, P.H. \& Kern, S. (1964) Acanthosis-like lesions from nicotinic acid. Archives of Dermatology, 89, 222.

VAN DIJK, E. (1963) Ichthyosiform atrophy of the skin associated with internal malignant disease. Dermatologica 127, 413.

WeINER, R.S. \& CoOPER, P. (1955) Multiple polyposis of the colon, osteomatosis and soft tissue tumours: report of a familial syndrome. New England Journal of Medicine, 253, 795.

WeSton, S.D. \& Wiener, M. (1967) Familial polyposis associated with a type of soft tissue lesion (skin pigmentation): report of 3 cases and a review of the literature. Diseases of the Colon and Rectum, 10, 311.

WhITE, J.W. \& PeRRY, H.O. (1969) Erythema perstans. British Journal of Dermatology, 81, 64.

Williams, R.C. JR (1959) Cancer accompanying dermatomyositis. Annals of Internal Medicine, 50, 1174.

Williams, J.P. \& KNUDSEN, A. (1965) Peutz-Jeghers syndrome with metastasizing duodenal carcinoma. Gut, 6, 179.

\section{Erratum}

Postgraduate Medical Journal, 46, October 1970.

The paper 'The definition and evaluation of skills required to obtain a patient's history of illness: the use of videotape recordings' was written by J. Anderson, J. L. Day, M. A. C. Dowling and K. W. Pettingale, not J. Anderson, J. L. Day, M. A. C. Dowling and K. W. Dowling as printed on the cover. We would like to apologise to $\mathrm{Dr}$ Pettingale for this error. 